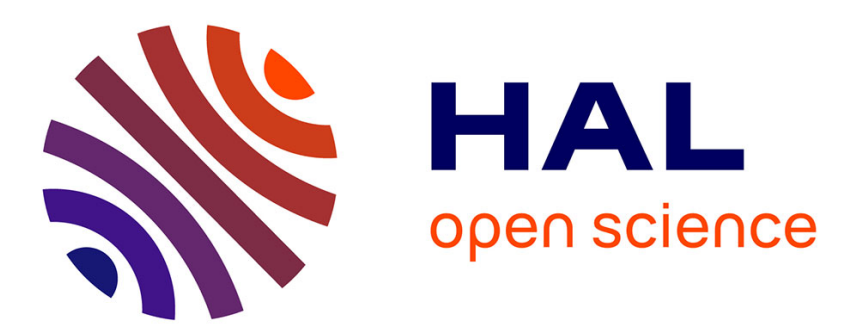

\title{
A dog's life: Multiple trauma and potential abuse in a medieval dog from Guimps (Charente, France)
}

Annelise Binois, Christophe Wardius, Pierre Rio, Anne Bridault, Christophe Petit

\section{To cite this version:}

Annelise Binois, Christophe Wardius, Pierre Rio, Anne Bridault, Christophe Petit. A dog's life: Multiple trauma and potential abuse in a medieval dog from Guimps (Charente, France). International Journal of Paleopathology, 2013, 3 (1), pp.39-47. 10.1016/j.ijpp.2013.02.001 . hal-01858415

\section{HAL Id: hal-01858415 https://hal.science/hal-01858415}

Submitted on 25 Oct 2019

HAL is a multi-disciplinary open access archive for the deposit and dissemination of scientific research documents, whether they are published or not. The documents may come from teaching and research institutions in France or abroad, or from public or private research centers.
L'archive ouverte pluridisciplinaire HAL, est destinée au dépôt et à la diffusion de documents scientifiques de niveau recherche, publiés ou non, émanant des établissements d'enseignement et de recherche français ou étrangers, des laboratoires publics ou privés. 


\title{
A dog's life: Multiple trauma and potential abuse in a medieval dog from Guimps (Charente, France) is $^{\text {is }}$
}

\author{
Annelise Binois ${ }^{\mathrm{a}, \mathrm{c}, *}$, Christophe Wardius ${ }^{\mathrm{a}, \mathrm{b}, \mathrm{c}}$, Pierre Rio $^{\mathrm{b}}$, Anne Bridault $^{\mathrm{c}}$, Christophe Petit ${ }^{\mathrm{a}, \mathrm{c}}$ \\ a Université de Paris 1 Panthéon-Sorbonne, UFR 03 Archéologie, 3 rue Michelet, F-75006 Paris, France \\ ${ }^{\mathrm{b}}$ ArchéoLoire, Parc d'activité de Villejames, 8 rue des Guérets, F-44350 Guérande, France \\ ' CNRS, UMR 7041 ArScAn, Equipe Archéologies environnementales, 21 allée de l'Université, F-92023 Nanterre Cedex, France
}

Keywords:

Animal palaeopathology

Dog

Animal abuse

Radius-curvus

Medieval archeology

\begin{abstract}
A B S T R A C T
Rescue excavations carried out around Guimps (Charente, France) in 2011 unearthed several medieval structures, including a silo containing a single dog burial. The animal, a young adult, exhibits numerous skeletal lesions. The excellent preservation of the remains allowed us to carry out a retrospective diagnosis and to demonstrate the presence of two independent pathologies, a radius-curvus and a medial patellar dislocation. These conditions are of traumatic origin, as are the many fractures the animal also displays. The possible causes of such multiple injuries are discussed and the chronology of the lesions and their skeletal distribution are examined in light of modern data. This leads us to suggest animal abuse as a probable cause and, as almost no comparable cases were found in the bibliographical record, raise the profile of the identification of animal abuse in archeology.
\end{abstract}

\section{Introduction}

The current trend in animal paleopathology is to abandon the discipline's previous 'interesting-specimens' approach and to integrate paleopathological data in comprehensive faunal studies (Vann and Thomas, 2006; Bartosiewicz, 2008; Thomas and Miklíková, 2008; Upex and Dobney, 2012). Resultant estimations of prevalence rates provide insight regarding health and injury in past animal populations and allow comparisons between different sites and periods, which therefore permits archeological and social interpretations of paleopathological data. As animal paleopathology advances, case studies continue to be significant. They are, of course, the building blocks of prevalence studies, and they offer the opportunity to develop rigorous differential diagnoses. Also significant is the fact that such cases often provide a lens through which broader issues may be viewed. The example presented here is significant in that it addresses social issues relating to the treatment of pets in medieval rural communities in France.

This paper presents a case study of a complete pathological dog skeleton dating to the 11 th-12th centuries AD from Guimps (Charente, France), describing the animal's osteological lesions, their

\footnotetext{
is The article is a contribution based upon a paper presented at the 2012 annual European meeting of the Paleopathology Association, Lille, France. This presentation was awarded the Cockburn Prize for the best Poster Presentation by a student.

* Corresponding author. Tel.: +33146692400.

E-mail address: annelise.binois@mae.u-paris10.fr (A. Binois)
}

differential diagnosis and their probable impact on the individual's life. The possible origins and significance of the multiple traumatic events will then be discussed, raising the issue of animal mistreatment and its identification on archeological material.

\section{Archeological context}

In 2011, ArchéoLoire carried out rescue excavations on a threehectare site in Guimps at the place known as Le Poteau (Fig. 1), prior to the construction of a housing estate (ArchéoLoire, excavation report pending). Previous archeological surveys had indeed shown the area covered part of a medieval rural settlement presenting continuous occupation between the 7th and the 14th century $\mathrm{AD}$, with the settlement taking on aristocratic characteristics from the 12th century onwards (Leconte, 2009). On the south-eastern edge of the site, mechanical excavations unearthed a group of silos and storage pits amidst a network of posterior ditches. Special attention was drawn to one of these storage pits, pit S31-F109, a flat-bottomed sub-oval pit with vertical walls $70 \mathrm{~cm}$ deep, which presented a single dog skeleton. The remains lay on the bottom of the pit, encased in dark silty clay containing much charcoal but very little other archeological material. The few pottery fragments were tentatively attributed typologically to the 10th-12th century. Subsequent radiocarbon analysis of the skeleton itself confirmed this result, dating the deposit to $1020-1160$ cal. AD (95.4\% prob., LTL12756A, $947 \pm 30 \mathrm{BP}$ ). No other structures from this phase were present in the near vicinity of the pit or appeared associated with it. 


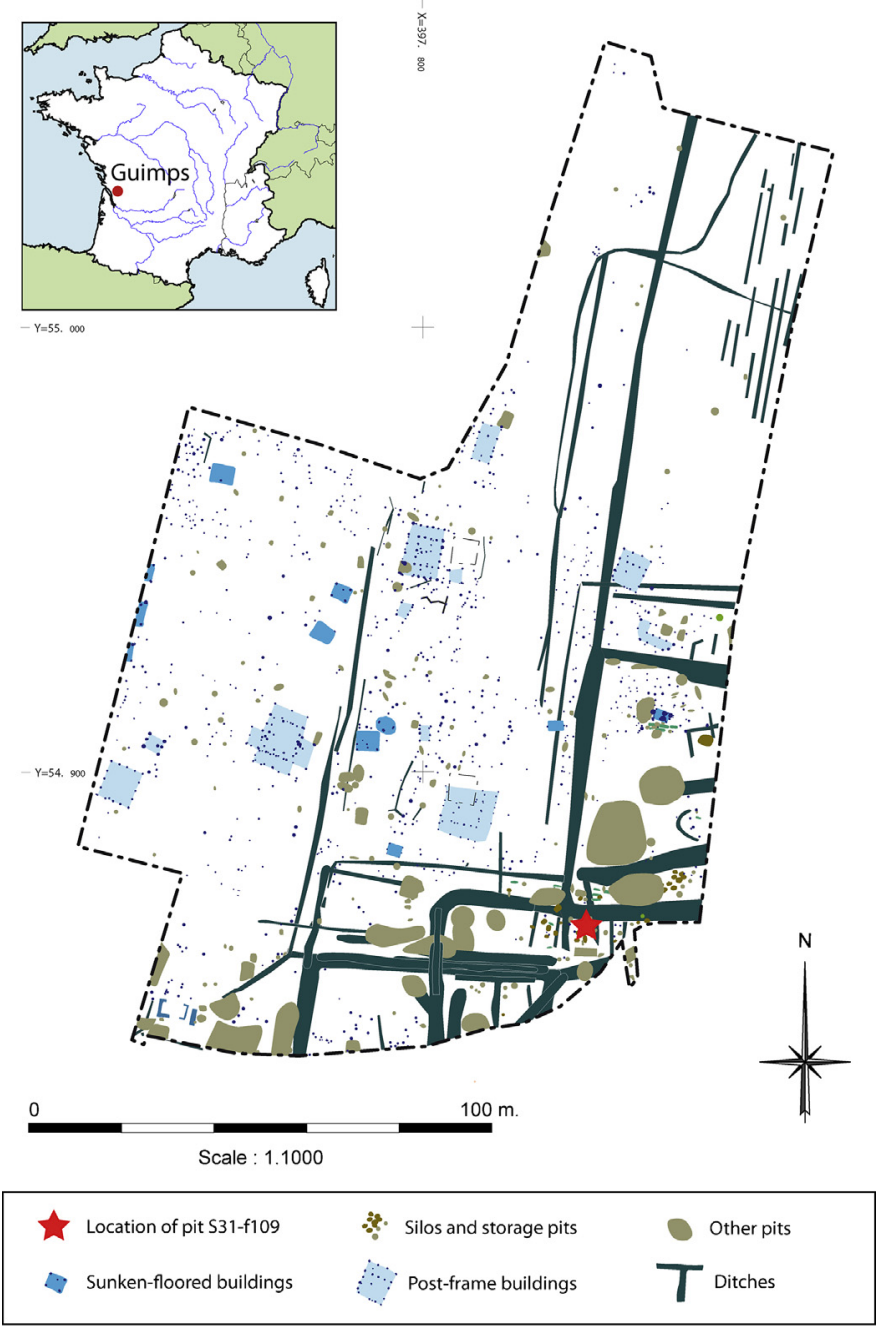

Fig. 1. Maps showing (a) the location of Guimps in France, (b) the area excavated, (c) the location of storage pit S31F109, graphics. Source: E. Boutonnet, courtesy of ArchéoLoire.

The animal was placed along the wall of the pit (Fig. 2), curled up in a natural position on its left flank with its front limbs tucked against its lower jaw, one hind leg folded and the other extended. Preservation was good except for the cranial vault, unfortunately destroyed by the mechanical excavator. The remains were fully articulated, displayed no sign of scavenger activity and sediment filled the thoracic volume; this shows the pit was filled in as soon as the dog was deposited. No other canine remains were found on site for this chronological phase, but earlier phases yielded a few disarticulated dog bones as well as the partial skeletons of an adult dog and a puppy.

\section{Case description}

The remains are of a medium-sized adult dog (Canis familiaris, L., 1758). Its skeleton is nearly complete, as only the left pelvis and left proximal femur, some caudal vertebrae and most of the small hand- and foot-bones are missing. The absence of a baculum, the negative humerus test (Ruscillo, 2006) and the conformation of the occipital bone (The and Trouth, 1976) point to a probable female. The dog was between 2 and 4 years old at the time of death, as evidenced by the fully erupted dentition, the slight dental wear (stage Ec, Horard-Herbin, 2000) and the epiphyseal fusion lines still visible on several long bones. It was of an estimated shoulder height of $49 \mathrm{~cm}$ (average of size calculations based on (GL humerus + GL radius) and on (GL femur + GL tibia), Harcourt, 1974), with midrange head width, snout length and snout width, and average bone slenderness (Harcourt, 1974). This conformation would be consistent with a smaller sheep-dog type or, more probably, with a common-breed dog. The adult dog from an earlier phase of the site (structure S35-F90) shows a similar height and build; this type seems to have been frequent all over Europe in medieval times (Harcourt, 1974; Teichert, 1993; Daróczi-Szabó, 2006).

Preservation of the bone surface is excellent, which allowed us to observe marks and lesions under optimal conditions. No cut marks or other anthropic marks are present on the remains, but the animal displays a large array of ante-mortem skeletal lesions, which affect no fewer than five skeletal regions and 16 individual bones (Fig. 3).

\subsection{Axial skeleton}

The skull presents a small depressed ante-mortem fracture in the facial area, involving the right nasal bone and the right incisivum. Healing of this fracture was underway at the time of death, the nasal bone fragments being united with a still clearly visible fracture line and very little callus; it can be estimated to have taken place about three weeks ante-mortem (Cruess et al., 1985). No other injuries are observed on the cranium, although since the 


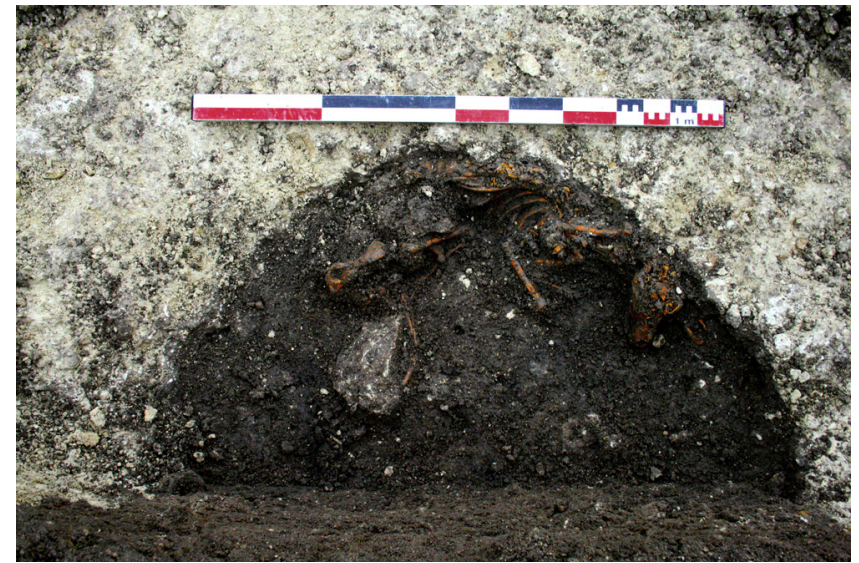

Fig. 2. Dog skeleton inside the excavated storage pit. Source: Photograph courtesy of ArchéoLoire.

cranial vault has unfortunately been destroyed during the excavation, other fractures cannot be excluded.

Traumatic injuries are also observed on the ribs, with adjacent right ribs 8, 9, 10 and 11 displaying well-healed fractures on the proximal third of the costal body. Ribs 9, 10 and 11 show only minor deformation, whereas rib 8 presents a slight misalignment (Fig. 4). Both the fractures observed on the skull and on the ribs are of the type resulting from direct trauma, consequences of a blow or impact applied directly to the fractured bones. In the case of the ribs, the force was applied to a somewhat broad area.

Six of the seven lumbar vertebrae also display pathology, with deformed spinous processes of reduced height, irregular enlargement and flattening of the dorsal edges and, in three cases, a slight left lateral deviation. One spinous process also displays a fracture line (Fig. 5). The transverse processes appear normal, as do the rest of the animal's vertebrae. These deformations are slightly unusual and may not immediately call to mind healed fractures; they nevertheless clearly resemble some of the pathological vertebra displaying healed fractures described by both Groot (2005) and Warren (2000). Since one at least does show a fracture line, they have thus been interpreted as such.

\subsection{Appendicular skeleton}

The most prominent pathological features of this individual affect its limbs, as the animal presents both a severely deformed left forearm and a significantly remodeled right stifle joint.

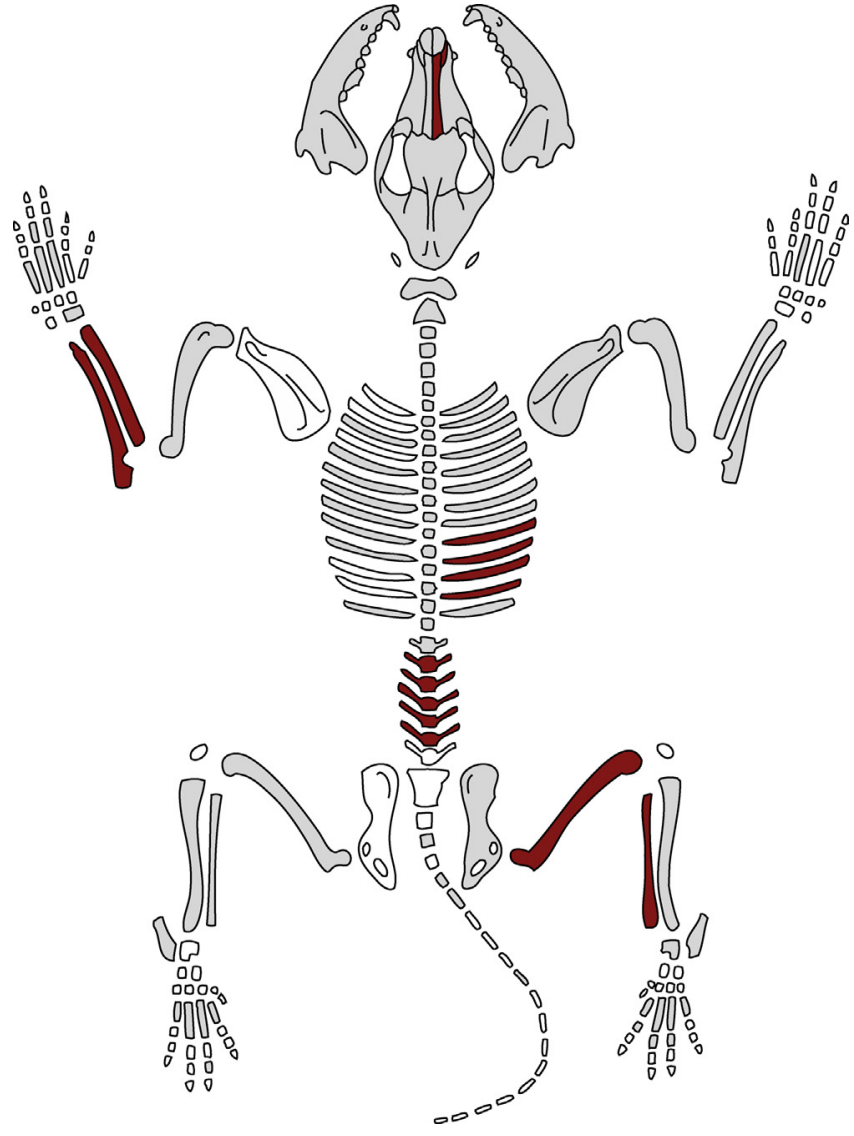

Fig. 3. Skeletal distribution of the observed lesions (light gray, normal bones; red, pathological bones; white, not recovered).

Source: Modified from Helmer (1987).

\subsubsection{Forearm lesions}

The dog's left radius appears bowed, displaying a marked mediocranial convexity (Figs. 6 and 7) associated with a slight external rotation and deviation of its distal end. The curvature is regular, and except for a small portion of ossified interosseous membrane, the cortical bone appears smooth and even, in all respects similar to the unaffected contralateral bone. Both proximal and distal articular surfaces are normal, and no joint osteoarthritis is noted. The left radius, due to its curve, presents a shorter GL (Von den Driesch, 1976) than the contralateral bone (145.2 mm compared with $149.2 \mathrm{~mm}$ ). The associated ulna also appears slightly curved in a cranial direction, but to a considerably lesser extent, and it displays otherwise no pathological modifications. Its length can

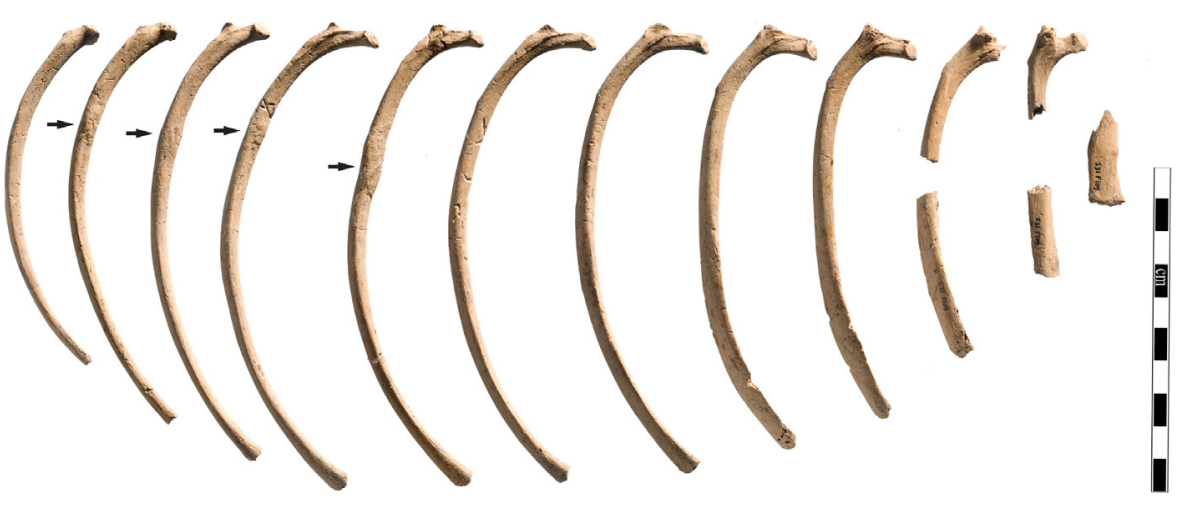

Fig. 4. Right rib cage, fractures of ribs 8-11, lateral view. 


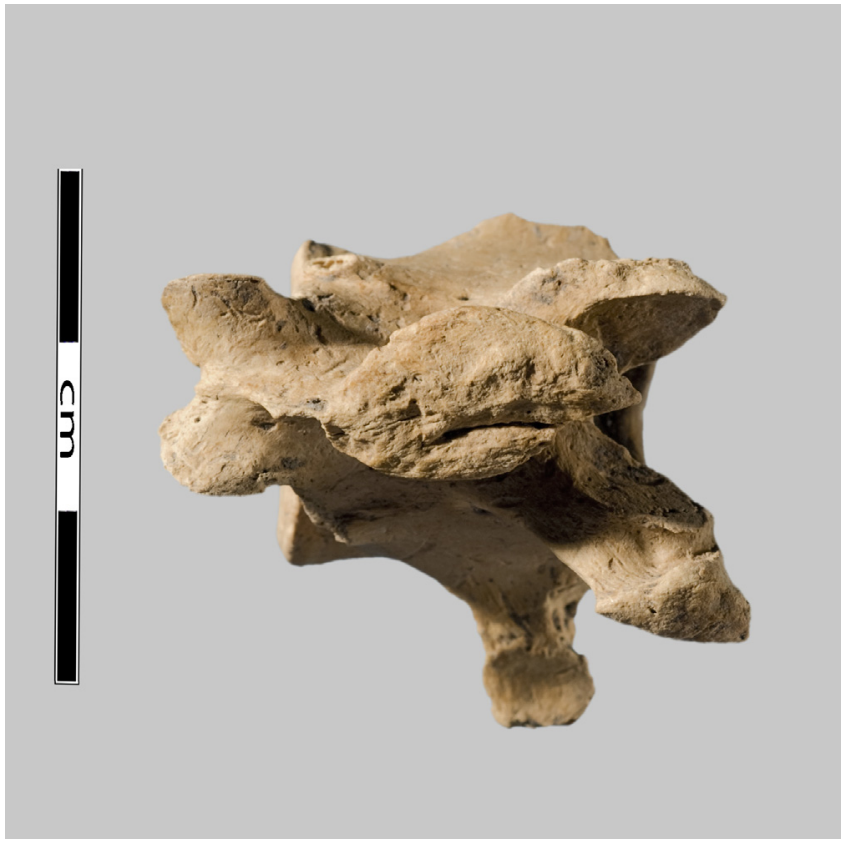

Fig. 5. Lumbar vertebra displaying anomalous spinous process, dorsal view.

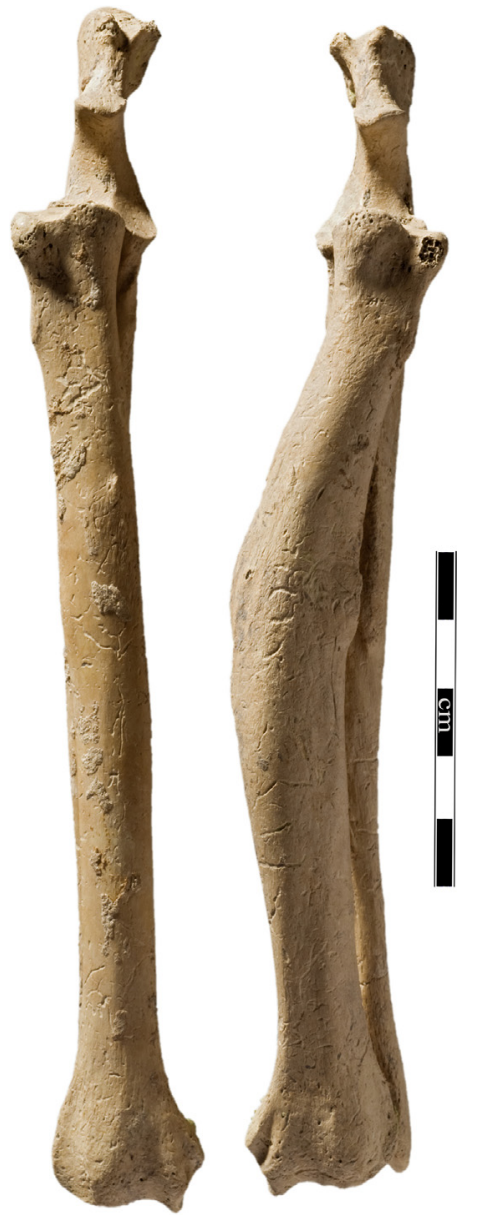

Fig. 6. Comparison of right and left radius-ulna, cranial view. unfortunately not be compared to the opposite bone, the latter being fragmentary.

Two diagnostic hypotheses can be considered for these lesions, both of traumatic origin: either a particular type of antebrachial growth deformity known as a radius-curvus, or an ancient, wellhealed and extensively remodeled radial fracture. To reach a conclusion, radiographic images were taken (Fig. 8). These show no sign of fracture either on the radius or on the ulna, and especially no radio-dense fracture line nor angulation of the medullary cavity. The cortical bone is homogeneous and of normal thickness, slightly thicker on the concave side, and the diameter of the medullary cavity is constant. Deposits of cancellous bone are visible in the medullary space, concentrated on the area of greatest curvature, and are presumably the signs of a non-specific inflammatory process.

These results do not exclude a very well-remodeled fracture; a greenstick fracture occurring in a young animal, in particular would not necessarily show any evidence of a fracture line, and the remodeling of the endosteal cavity could explain the lack of constriction of the medullary space. However, such a fracture displacing medially and cranially both radial fragments would probably be a consequence of direct trauma occurring from a laterodorsal direction. That such trauma could fracture the radius without involving the ulna and that such a fracture could heal without engendering synostoses between the two bones appears highly unlikely.

The second diagnostic hypothesis is a radius-curvus. This condition is classified among the antebrachial growth deformities and results from premature closure of the distal ulnar physis (growth plate) (Troger and Viguier, 2003; Tilley and Smith, 2011a). It is caused by either direct (impact, blow) or indirect (poor landing after a jump or a fall) trauma to the distal ulna, occurring in actively growing dogs, most often between the age of 4 and 7 months and always before the age of 10 months. Large breeds with rapid growth are predisposed, as $79 \%$ of cases occur in animals of an adult weight over $25 \mathrm{~kg}$ (Troger and Viguier, 2003). The Guimps dog is unlikely to have exceeded that mark; actual breeds of similar shoulder height usually weigh between 15 and $20 \mathrm{~kg}$ according to conformation.

Longitudinal growth of the forearm is dependent on the synchronous growth of the radius and the ulna. If two growth plates, one distal and one proximal, contribute to the elongation of the radius, the inter-articular growth of the ulnar shaft depends on its distal growth plate only.

In dogs, the specific cone-like shape of the distal ulnar growth plate makes it particularly vulnerable to crushing and shearing, and its anatomical position exposes it to frequent trauma (Troger and Viguier, 2003). Premature closure has obvious consequences: the ulna stops growing and remains shortened, while the radius will continue growing. Being hampered both by the elbow and the carpal joints, it will bend away from the ulna, acquiring a distinctive cranial or cranio-medial curvature, the so-called radius-curvus. The radius will also twist at its distal extremity, with an external rotation and a lateral deviation of the distal epiphysis, resulting in a malposition of the forefoot, with a valgus deformity and a supination. In some cases, malarticulation of the elbow joint may occur, usually causing painful joint restriction and early onset osteoarthritis (Troger and Viguier, 2003; Tilley and Smith, 2011a).

Most of these osteological signs of radius-curvus can be found in this dog, namely a cranio-medial curvature of the radius with an external rotation and a lateral deviation of its distal end. Because most carpal bones are absent, checking for a forefoot malposition was not possible, but the event seems likely. The slight ulnar curve, unusual in radius-curvus cases, could be explained by an incomplete closure of the distal ulnar physis, with growth persisting at a decreased rate on the cranial side of the growth plate. This hypothesis would also 


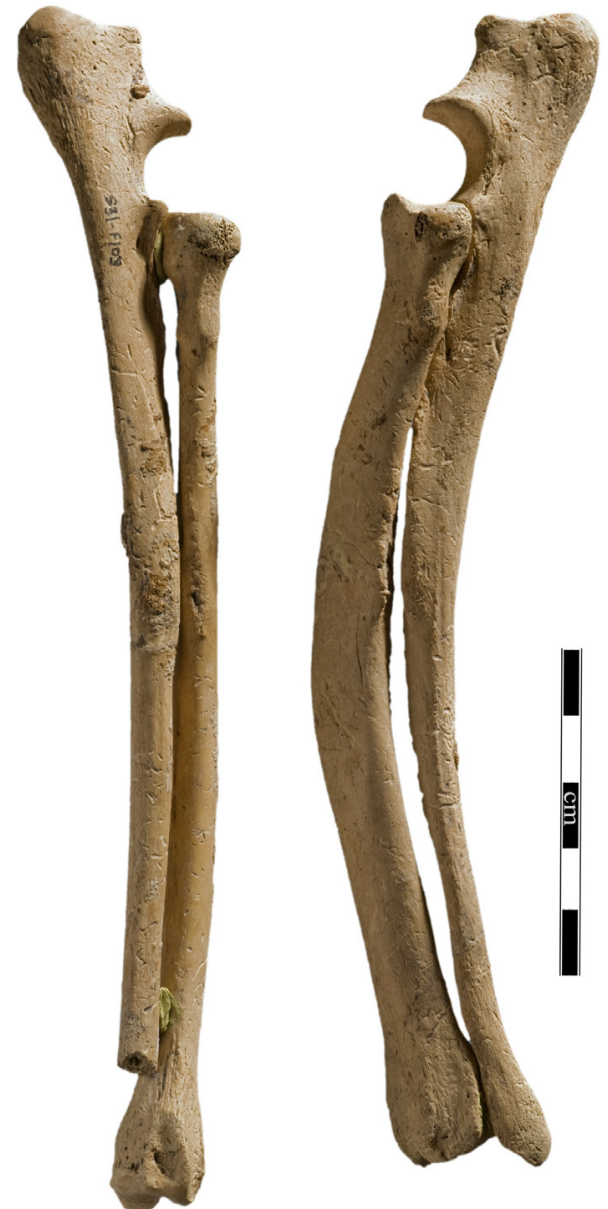

Fig. 7. Comparison of right and left radius-ulna, lateral view.

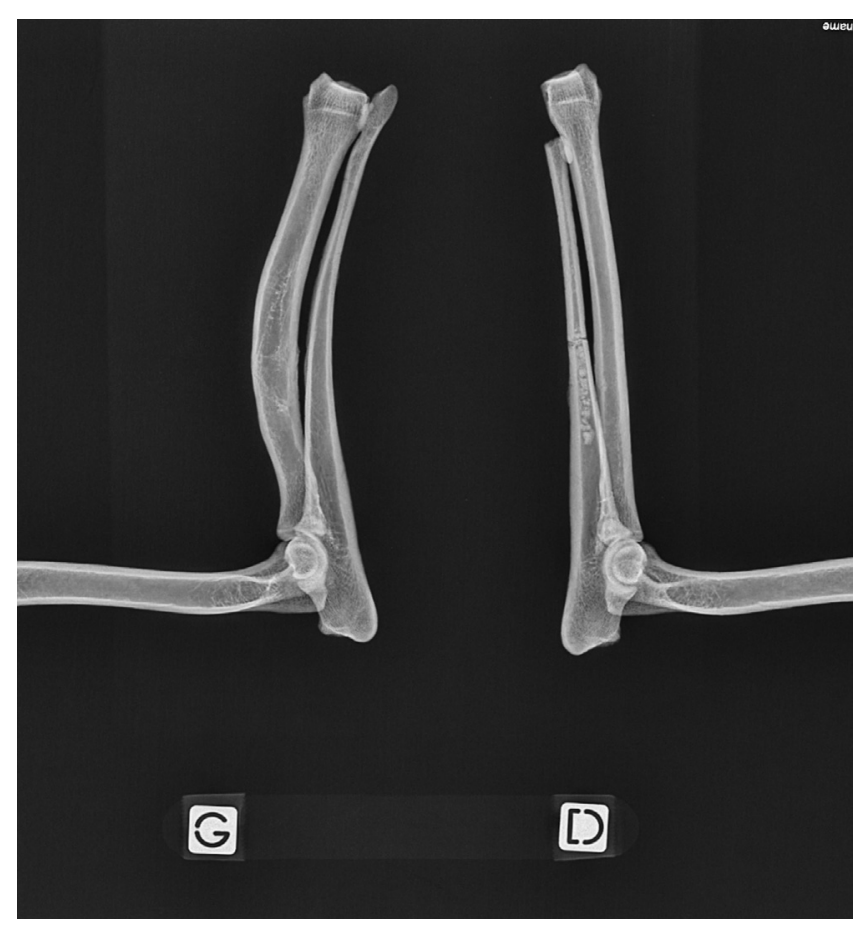

Fig. 8. Radiographic image of both antebrachium, medial view (G, left; D, right). explain the limited shortening of the diseased forearm compared to the opposite limb and the animal's perfectly sound elbow joint.

A diagnosis of radius-curvus consequently fits this paleopathological case quite well. Confirmation involves demonstrating the actual shortening of the affected ulna. As the distal end of the contralateral bone is fractured, no numerical values could be established, but visual examination of the bones confirms the shortening of the left ulna (Fig. 7). Radius-curvus is therefore the best diagnostic hypothesis for the lesions the dog exhibits, which makes this the first description of an antebrachial growth deformity in an archeological animal.

\subsubsection{Stifle lesions}

Finally, the animal's right stifle (hind limb) joint must be discussed: the distal femur, the tibial plateau and the fibula all display pathology. A traumatic origin is again implicated, as the fibula shows a healed displaced fracture on its proximal diaphysis.

The most noticeable lesions are observed on the distal femur, however (Fig. 9). Instead of forming a groove, the trochlea appears convex with a virtual disappearance of its articular reliefs: the medial lip is non-existent and the lateral lip, much reduced, seems folded back in a latero-caudal direction; the two condyles as well show deformations of their articular surfaces. The cortical surface is smooth and shows neither osteolysis nor new bone formation, but nevertheless displays a degree of post-depositional erosion significantly greater than the contralateral limb, a sign of increased fragility.

The corresponding tibial plateau also shows important surface remodeling (Fig. 10). Neither intercondylar tubercle is discernible and the medial and the lateral articular surfaces appear merged in a single, almost-flat surface. The medial condyle is reduced and displaced cranially whereas the lateral condyle is enlarged and shows caudal lipping indicating an increase in the weight borne by the articular surface.

Radiographs of the stifle (with the exception of the patella, unfortunately missing from the skeleton) did not show any modification in bone structure of any skeletal element and in particular neither disuse osteopenia nor increased subchondral bone density (Fig. 11).

The femoral lesions and especially the absence of a trochlear groove are evidence of a patellar luxation, presumably grade III or over, based on trochlear morphology (Nunamaker, 1985; Pucheu et al., 2003). The tibial lesions then indicate the direction of the dislocation. Indeed, the patella is included in the tendon of the

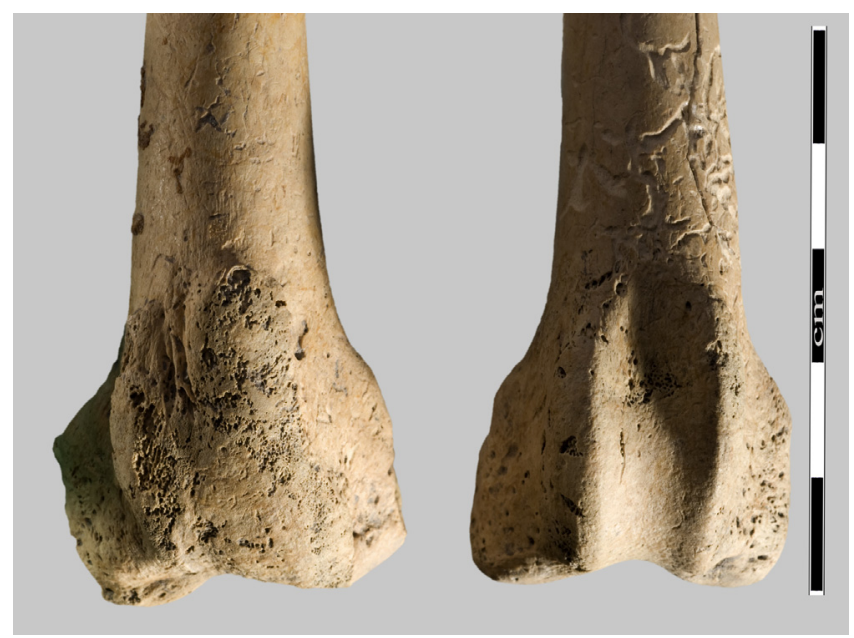

Fig. 9. Femur, trochlear groove, cranial view, pathological articular surface (left in picture) in comparison to contralateral limb. 


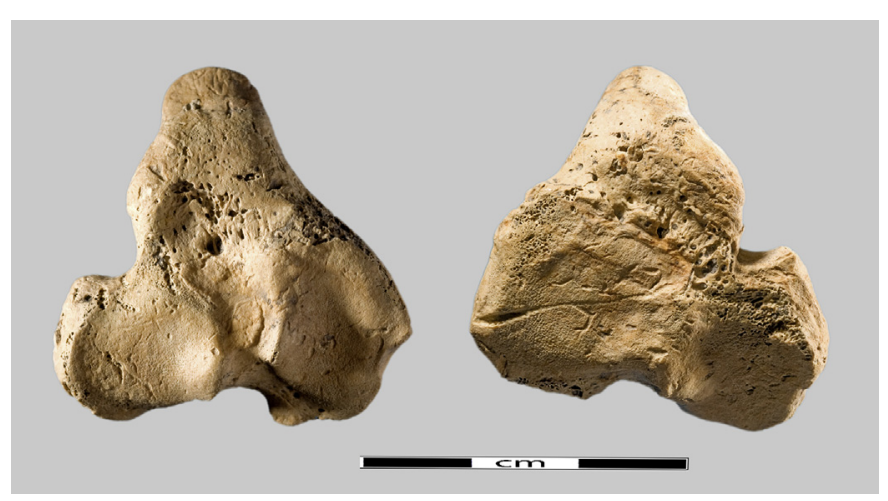

Fig. 10. Tibial plateau, proximal view, pathological articular surface (right in picture) in comparison to contralateral limb.

quadriceps femoris, tendon that inserts itself distally on the tibial crest. Any horizontal displacement of the kneecap, such as in patellar luxation, implies a displacement of the tendon and thus of the tibial crest, and thereby a rotation of the tibia on its greater axis. If weight is still borne on the injured limb, the articular surfaces of the tibial plateau will then be gradually remodeled in response to the new contact areas with the femoral condyles. In the present case, the animal exhibits a cranial displacement of the medial surface and a caudal displacement of the lateral surface, which signify an internal rotation of the tibial crest, typical of a medial patellar luxation.

Medial patellar dislocations are the most common orthopedic complaint in present-day dogs (Pucheu et al., 2003) and are in

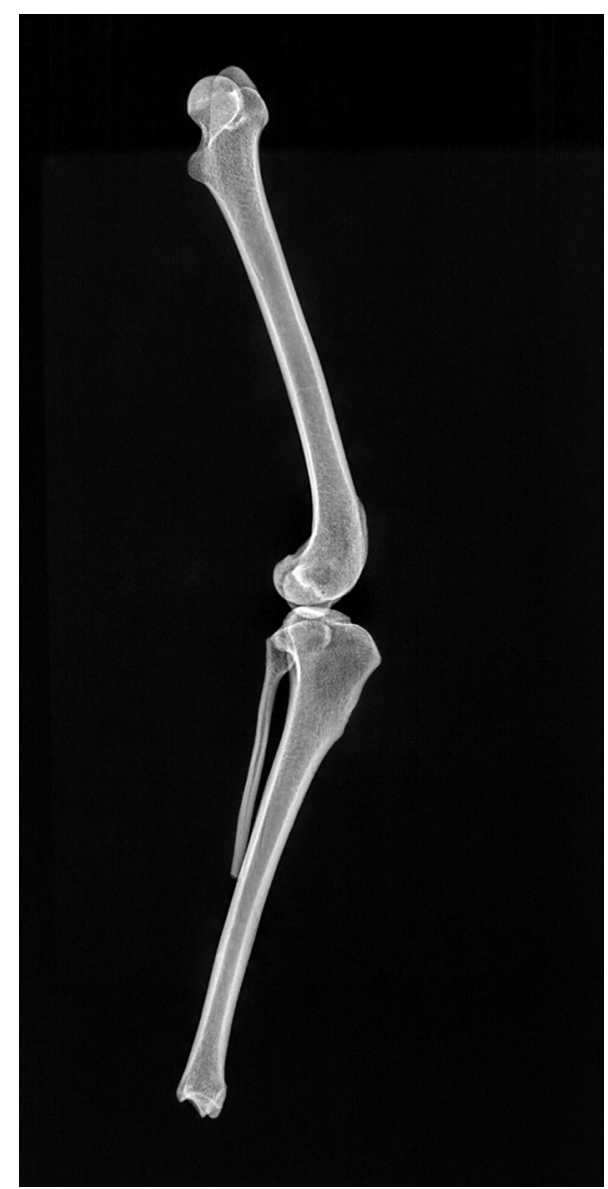

Fig. 11. Radiographic image of right stifle joint, lateral view. most cases congenital. The affected animals are typically of toy or dwarf breeds and present uni- or bilateral dislocations from an early age on, associated with pelvic, femoral and/or tibial deformities (Tilley and Smith, 2011b). Much rarer, traumatic dislocations in osteologically sound animals also exist; they are always unilateral and most often medial, as trauma occurring from the medial side is rare.

In the case of the dog from Guimps, we suggest the origin of the dislocation is traumatic. The animal is not in the typical epidemiological profile for congenital dislocations: medium-sized, very 'average dog'-typed animals are the dogs that are least prone to congenital dislocations, even if this condition's prevalence in this group remains higher than traumatic dislocations. Further, while many congenital cases suffer from deformities of either hip or contralateral stifle joints, both joints appear perfectly sound in this animal. More importantly, the skeletal remains display a healed proximal fibular fracture, which is evidence of trauma to the stifle joint. The location of the fracture on the fibula and the anatomic position of this bone show the direction of the blow would be consistent with that necessary to induce a traumatic dislocation.

Patellar luxations, whether traumatic or congenital, were probably not rare in medieval times. The associated lesions are however sometimes discrete, and it seems our dog would be the first described archeological case, as no other example was found in the archeological literature.

\section{Interpretation}

\subsection{Origin and significance of the lesions}

The osteological lesions of the Guimps dog are interesting per se in terms of pathology, providing a unique glimpse of medieval dog traumatology. Their main interest, however, lies elsewhere, in the significant social implications that arise from this clinical picture and in the light it sheds on an important aspect of the relationship between humans and their domestic animals.

The remains display no fewer than five independent lesions of traumatic origin, which occurred in at least three separate events: the trauma to the distal ulnar growth plate had to occur before the age of ten months for a radius-curvus to arise, whereas the facial fracture took place no earlier than one month prior to death. The stifle joint injury can be placed between these two events; the absence of femoral and tibial bone-shaft deformities point to trauma occurring in adulthood, but the extent of the articular damage and the well-healed fibular fracture demonstrate the lesions had been remodeling for a few months at least. The rib and vertebral fractures, unfortunately, cannot be given a specific timeline: they are well-healed and could have happened at any time between youth and a few months prior to death; typically, rib fractures in dogs heal in 8-16 weeks (Cruess et al. 1985).

What could therefore have caused such repeated injury? Each of the lesions taken individually could have any number of origins: for instance, a kick from a cow, a hunting injury inflicted by a boar or a collision with a vehicle could each explain the broken ribs. However, as stated by the principle of diagnostic parsimony, unique diagnostic hypotheses, when possible, are more probable than multiple ones. To be satisfying, such a hypothesis should explain not only the existence of all of the lesions, but their skeletal distribution and their chronology as well. In the present case, the clinical picture displayed by the dog is very evocative of a unique causal agent: animal abuse.

While epidemiological data on abused animals are still sparse and incomplete, there seems to be a consensus that blunt force 
trauma is the most common form of abuse, and that certain patterns of injury can be considered highly suggestive of it (Munro and Thrusfield, 2001; Sinclair et al., 2006; Merck, 2007). These patterns include multiple fractures at different stages of healing, especially when located on the head, the ribs, or the spine. If these specific areas have been at first identified by clinical findings in abused dogs, their locations can be explained by behavioral considerations both of dogs and of people. Two common forms of dog abuse are kicking and hitting with a stick. In medium-sized animals, the first will mostly injure the belly, the ribs and the nose; the latter, in a downward movement, will injure mostly the top of the head and the spine. As to the dog, it will respond to aggression in three main ways: by returning aggressiveness, thus presenting its head; by flight, presenting its hind quarters and its lower back; or by protective curling up, exposing its sides and its spine. A second blow is therefore likely to encounter these locations (Merck, 2007). As the dog from Guimps presented nose, rib and spine injuries in different stages of healing, as well as injuries of a foreleg and of a hind-leg, abuse appears quite probable.

\subsection{Implications for the dog's life}

In any case, and whatever the origin of the traumatic injuries the dog displays, the animal survived at least three episodes of violent trauma which left osteological traces, then died prematurely, probably between the ages of two and four. These healed and healing lesions can help us to gain insight on the dog's life, its death and its status. What was its life like? Of what did it die? Was it a pet, a work animal, a pariah dog?

Apart from the very recent facial fracture, all of the many identified fractures are well-healed and present little or no misalignment; furthermore, none is located in an articular zone. It therefore seems likely that, at the time of the dog's death, these fractures no longer affected its health. The same can also be said of the radius-curvus: while the condition can be painful during growth, once the bone has reached its full size the body adapts to the deformation and compensates for the shortening of the affected limb. In most cases, as long as there is no elbow malarticulation, the adult dog does not limp or only very discretely, and demonstrates no pain (Troger and Viguier, 2003).

The patellar luxation and stifle joint lesions, on the other hand, reveal a serious joint instability, which would mechanically imply a severe lameness. Even though the remodeling of the tibial plateau shows some weight was still borne on the leg, this limp was probably serious enough to impair the dog's usefulness as a work animal.
Pain is however difficult to assess: if we can be relatively confident about the existence and the importance of a limp because mechanical causes are involved, there is in such cases no correlation between the severity of the lameness and the severity of the pain encountered (Nunamaker, 1985).

It is therefore difficult to estimate the dog's general condition at the time of death; it may have been reasonably healthy, albeit with a disabled hind-leg. The cause of its premature death is equally inaccessible to us. The injuries observed are all non-fatal, and if mistreatment was responsible for death, for instance by a heavy blow to the head or one causing internal injury, no traces of it were left on the available bones, and very many other causes can be considered.

Finally, what care was given to this animal during its lifetime? The fractures the dog displays are all of the type that require no splinting and heal well spontaneously, and no specific treatment or human intervention was needed for their recovery. Likewise, the fact that the dog survived its injuries does not imply that it was cared for or fed: present-day pariah dog populations demonstrate limping or even three-legged dogs can fare reasonably well on their own. This does not, however, mean that no care was ever given to the animal. After all, the fact that its body shows no sign of post-mortem exploitation such as skinning and was buried in a natural position alone in a silo, rather than thrown amidst the waste also present on site, shows that some attention at least was given to the disposal of the cadaver.

\subsection{Discussion}

It is not surprising to detect a case of mistreatment in a medieval dog. People have beaten their dogs for probably as long as people have had dogs, and the fact is acknowledged in textual sources, both literary and judiciary, from the beginning of antiquity (Bodson, 1986). Even though no reliable epidemiological evidence exists, abuse of domestic dogs is still frequent today, and it can be surmised that, because of the different social representation of the status of animals (Thomas, 2005), and because of the omnipresent threat of rabies (Fig. 12), the phenomenon was even more common in the Middle Ages.

What is surprising, on the other hand, is the lack of data on animal abuse in the archeological record. Our bibliographical researches unearthed no comparable published cases for medieval France, and only one for medieval Europe, a partial dog skeleton from Kilkenny (Ireland), which displayed evidence of fractures on several thoracic vertebra and on four ribs, two right and two left (Murphy, 2005). All fractures were in an early state of healing at

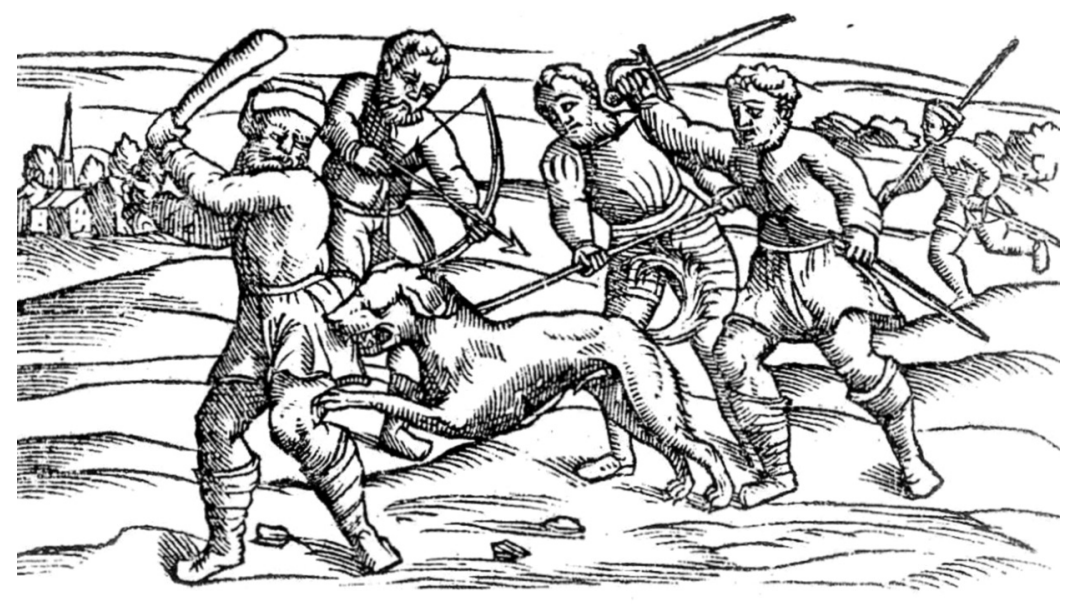

Fig. 12. Killing of a rabid dog, woodcut engraving, 1575, spanish edition of De materia medica by Dioscorides. Source: Wikimedia Commons. 
time of death and probably occurred simultaneously; the author ascribes them to a series of heavy blows or to a fall, the latter supposition being in our opinion unsubstantiated by the distribution of trauma. An interesting study by Teegen also addresses the issue of battered dogs in medieval Germany (Teegen, 2005). It is unfortunately based on rib and vertebral fracture rates in a corpus of disarticulated bones, thus preventing identification of multiple fractures and of different healing stages in single animals, and therefore compromises the conclusions. No other relevant references were found.

This scarcity of data is not a consequence of lack of material. Complete dog skeletons are common finds in archeology irrespective of location and of period, so common in fact that many are overlooked. Neither is the lack of testimonies of mistreatment a sign of the infrequency of animal abuse. Almost all zooarchaeological fracture incidence studies on disarticulated collections show a significantly higher rate of fractures in dogs than in other domestic animals, even of similar height and/or body weight (for example, Groot, 2005; Murphy, 2005; Bartosiewicz, 2008; Grimm, 2008), and skeletal element distributions favor rib (Warren, 2000; Groot, 2005; Murphy, 2005; Bartosiewicz, 2008), cranial (Bartosiewicz, 2008; Grimm, 2008) and vertebral fractures (Warren, 2000). These findings are consistent with the injury pattern of animal abuse, and non-accidental trauma could therefore be a likely cause of fractures in archeological dogs.

The explanation therefore may lie in unpublished data and unstudied material; it could be that until now, multiple traumatic injuries in dogs have failed to attract attention from archeologists or have not been deemed worthy of publication. The issue of animal abuse is nonetheless an important one in the exploration of the history of human-animal relationships and in the understanding of cultural attitudes toward animals. It therefore deserves further research.

\section{Conclusion}

The S31-f109 dog, a near-complete skeleton discovered in the medieval phase of the rural settlement of Guimps, is important for several reasons. Firstly, since animal remains are normaly dispersed, animal paleopathology is often unable to offer reliable diagnoses. The excellent preservation of these remains and the unambiguous lesions they display allow us to achieve a true retrospective diagnosis and to detect with a low margin of error two independent pathologies: a radius-curvus and a medial dislocation of the patella. Both conditions are described here for the first time in the zooarchaeological record. Moreover, the interest of the case is not limited to a paleopathological curiosity: the number of lesions, their skeletal distribution and their various healing stages demonstrate a pattern of injury typical of animal abuse. This issue has not been thoroughly investigated in archeology yet, and it appears this dog provides the most convincing case published for medieval Europe. This evidence from a battered dog raises the question of attitudes toward domestic animals in the Middle-Ages. Historical and statistical data show abuse may have been frequent; greater attention to traumatic injuries in complete animal skeletons will provide an essential, independent line of evidence.

\section{Acknowledgements}

I am much grateful to Serge Oboukhoff, of the MAE René Ginouvès, for the wonderful photographs he took of the remains, and to Sandy Santin and Marion Binois of the Ecole Nationale Vétérinaire d'Alfort for their radiographs of the lesions. I would also like to express my appreciation to the reviewers of this article for their helpful comments.

\section{References}

Bartosiewicz, L., 2008. Description, diagnosis and the use of unpublished data in animal palaeopathology: a case study using fractures. Veterinarija Ir Zootechnika 41 (63), 12-24.

Bodson, L., 1986. The welfare of livestock and work animals in ancient Greece and Rome. Medical Heritage 2 (4), 244-249.

Cruess, R., Dumont, J., Newton, C., Rhinelander, F., 1985. Healing of bone. In: Newton, C., Nunamaker, D. (Eds.), Textbook of Small Animal Orthopaedics. J. B. Lippincott, Philadelphia, pp. 35-48.

Daróczi-Szabó, M., 2006. Variability in medieval dogs from Hungary. In: Snyder, L., Moore, E. (Eds.), Dogs and People in Social Working Economic or Symbolic Interaction. Oxbow, Oxford, pp. 85-95.

Grimm, J.M., 2008. Break a leg: animal health and welfare in medieval Emden, Germany. Veterinarija Ir Zootechnika 41 (63), 49-59.

Groot, M., 2005. Understanding past human-animal relationships through the analysis of fractures: a case study from a Roman site in the Netherlands. In: Davies, J., Fabiš, M., Mainland, I., Richard, M., Thomas, R. (Eds.), Diet and Health in Past Animal Populations: Current Research and Future Directions. Oxbow, Oxford pp. 40-50.

Harcourt, R.A., 1974. The dog in prehistoric and early historic Britain. Journal of Archaeological Science 1, 151-175.

Helmer, D., 1987. Fiches descriptives pour les relevés d'ensembles osseux animaux Fiches d'ostéologie animale pour l'archéologie. Série B: Mammifères. Juan-lesPins: Editions APDCA.

Horard-Herbin, M.-P., 2000. Dog management and use in the late Iron Age: the evidence from the Gallic site of Levroux (France). In: Crockford, S. (Ed.), Dogs Through Time: An Archaeological Perspective. BAR, International Series, No. 889, Oxford, pp. 115-121.

Leconte, S., 2009. Guimps, Le Poteau, Charente. Une occupation du Haut Moyen Âge au XIIIe siècle. INRAP Grand Sud-Ouest, Rapport de diagnostic inédit.

Merck, M., 2007. Veterinary Forensics: Animal Cruelty Investigations. WileyBlackwell, Ames.

Munro, H.M.C., Thrusfield, M.V., 2001. Battered pets: non-accidental physical injuries found in dogs and cats. Journal of Small Animal Practice 42, 279-290

Murphy, E.M., 2005. Animal palaeopathology in historic Ireland: a review of the evidence. In: Davies, J., Fabiš, M., Mainland, I., Richard, M., Thomas, R. (Eds.), Diet and Health in Past Animal Populations: Current Research and Future Directions. Oxbow, Oxford, pp. 8-23.

Nunamaker, D.M., 1985. Patellar luxation. In: Newton, C., Nunamaker, D. (Eds.), Textbook of Small Animal Orthopaedics. J.B. Lippincott Company, Philadelphia, pp. 972-984.

Pucheu, B., Barreau, P., Duhautois, B., 2003. Pathogénie et diagnostic des luxations rotuliennes. Affections ostéo-articulaires du chien et du chat en croissance. Le Point Vétérinaire 34, 54-56.

Ruscillo, D., 2006. The table test: a simple technique for sexing canid humeri. In: Ruscillo, D. (Ed.), Recent Advances in Ageing and Sexing Animal Bones. Oxbow, Oxford, pp. 62-67.

Sinclair, L., Merck, M., Lockwood, R., 2006. Forensic Investigation of Animal Cruelty: A Guide for Veterinary and Law Enforcement Professionals. Humane Society Press, Washington, DC.

Teegen, W.R., 2005. Rib and vertebral fracture in medieval dogs from Haithabu, Starigard and Schleswig. In: Davies, J., Fabiš, M., Mainland, I., Richard, M., Thomas, R. (Eds.), Diet and Health in Past Animal Populations: Current Research and Future Directions. Oxbow, Oxford, pp. 345-348.

Teichert, M., 1993. Size and utilisation of the most important domesticated animals in Central Europe from the beginning of domestication until the late middle ages. In: Clason, A., Payne, S., Uerpmann, P. (Eds.), Skeletons in Her Cupboard. Festschrift for Juliet Clutton-Brock. Oxbow, Oxford, pp. 235-238.

The, T.L., Trouth, C.O., 1976. Sexual dimorphism in the basilar part of the occipital bone of the dog (Canis familiaris). Acta Anatomica 95, 565-571.

Thomas, R., 2005. Perceptions versus reality: changing attitudes towards pets in medieval and post-medieval England. In: Pluskowski, A. (Ed.), Just Skin and Bones? New Perspectives on Human-Animal Relations in the Historic Past. British Archaeological Reports International Series 1410, Oxford pp. 95-105.

Thomas, R., Miklíková, Z., 2008. Introduction: current research in anima palaeopathology, in: Current Research in Animal Palaeopathology: Proceedings of the Second ICAZ Animal Palaeopathology Working Group Conference pp. $1-2$.

Tilley, L.P., Smith, F.W., 2011a. Antebrachial growth deformities. In: Tilley, L.P., Smith, F.W.(Eds.), Blackwell's Five-Minute Veterinary Consult: Canine and Feline., fifth ed. Wiley-Blackwell, Ames, pp. 88-89.

Tilley, L.P., Smith, F.W., 2011b. Patellar luxation. In: Tilley, L.P., Smith, F.W. (Eds.) Blackwell's Five-Minute Veterinary Consult: Canine and Feline. , fifth ed. WileyBlackwell, Ames, pp. 1036-1038.

Troger,J.-C., Viguier, E., 2003. Physiopathogénie du radius curvus chez le chien. Affections ostéo-articulaires du chien et du chat en croissance. Le Point Vétérinaire $34,100-115$.

Upex, B., Dobney, K., 2012. More than just mad cows: exploring humananimal relationships through animal paleopathology. In: Grauer A.L. (Ed.), A Companion to Paleopathology. Wiley-Blackwell, Ames, pp. 191-213. 
Vann, S., Thomas, R., 2006. Humans, other animals and disease: a comparative approach towards the development of a standardised recording protocol for animal palaeopathology. Internet Archaeology, 20.

Von den Driesch, A., 1976. A Guide to the Measurement of Animal Bones from Archaeological Sites. Peabody Museum Bulletin 1. Harvard University, Cambridge.
Warren, D., 2000. Palaeopathology of Archaic dogs from the North American Southeast. In: Crockford, S.J. (Ed.), Dogs Through Time: An Archaeological Perspective. Proceedings of the First ICAZ Symposium on the History of the Domestic Dog. British Archaeological Reports International Series, Oxford, pp. 105-114. 